\title{
DROPLET SIZE CLASSIFICATION OF AIR INDUCTION FLAT FAN NOZZLES
}

\author{
Zbigniew Czaczyk ${ }^{1 *}$, Greg Kruger ${ }^{1}$, Andrew Hewittt,3 \\ ${ }^{1}$ West Central Research and Extension Center, University of Nebraska-Lincoln \\ 402 West State Farm Road, North Platte, NE 69101-7751, USA \\ ${ }^{2}$ Lincoln University, Engineering Drive, Christchurch 7640, New Zealand \\ ${ }^{3}$ The University of Queensland, Gatton, Queensland 4343, Australia
}

Received: April 10, 2012

Accepted: August 24, 2012

\begin{abstract}
Measurements were made of the droplet size for a series of air induction flat fan nozzles produced by Marian Mikołajczak Agro Technology (MMAT) and Coorstek. The MMAT nozzles, according to International Organization for Standardization (ISO) standard sizes, are typical single jet (long body, $37 \mathrm{~mm}$ ) with 025, 03, and 04 orifice sizes; (short body, $21 \mathrm{~mm}$ ) with 02, 025, 03 and 04 orifice sizes; and twin jet (short body, $21 \mathrm{~mm}$ ) with 03 and 04 orifice sizes. Ceramic air induction flat fan nozzles of the Albuz AVI series (Coorstek, France) with the orifice size 01, 02 and 03 were tested. The sprays were described using the following droplet size parameters: $\mathrm{D}_{\mathrm{v} 10}, \mathrm{D}_{\mathrm{v} 50}, \mathrm{D}_{\mathrm{v} 90}$, relative span (RS), spray volume (\%) in size fractions $<100 \mu \mathrm{m}$ and $100 \div 200 \mu \mathrm{m}$. The sprays were also classified according to American Society of Agricultural Engineers (ASAE) standard S572.1 (ASAE 2009).
\end{abstract}

Key words: air induction nozzles, drift reduction, droplet characteristics, droplet size, MMAT nozzles, spray classification

\section{INTRODUCTION}

In Poland, there are no governmental rules for the mandatory evaluation of spraying equipment. There are also no defined methodologies for the development of independent technical information about the working characteristics of sprayers, nozzles, not are there recommended working parameters for different application practices. This study provides some useful information on the characteristics of spraying parameters for specific nozzles based on droplet size performance. This information should be useful for sprayer operators who must determine the right working parameters of field sprayers. Air induction nozzles which have been manufactured since 2011 by Marian Mikołajczak Agro Technology (MMAT) from Leszno, were tested. Some of the working parameters for these nozzles have already been reported by Czaczyk (2011b): $\mathrm{D}_{\mathrm{v} 10^{\prime}} \mathrm{D}_{\mathrm{v} 50^{\prime}}, \mathrm{D}_{\mathrm{v} 90^{\prime}}, \mathrm{V}_{<95}, \mathrm{~V}_{<250^{\prime}}$ $\mathrm{V}_{>500}$ and spraying classes. It was determined that the quality of non air induction nozzles, series relative span (RS) and AZ produced by MMAT, meet the basic international requirements: wear rate, quality of cross distribution (variation coefficient $-\mathrm{CV}$ ), color code and flow rate (Czaczyk 2011a), and also $\mathrm{D}_{\mathrm{v} 10^{\prime}}, \mathrm{D}_{\mathrm{v} 50}, \mathrm{D}_{\mathrm{v} 90}, \mathrm{~V}_{<100}$, relative span, and spraying classes (Czaczyk 2012). The ceramic Albuz air induction flat fan nozzles were included in this study as a reference for international standards in spray atomization. For many years, research and development of spraying techniques has focused largely on reducing spray drift potential (Southcombe et al. 1997; Hewitt 2001;
Czaczyk and Kleisinger 2002; Guler et al. 2007; Nuyttens et al. 2007a; Hewitt 2008b). Lund (2000) and several other researchers suggested that drift potential of a spray can be related to the proportion of small droplets $(<100$ $\mu \mathrm{m}$ diameter) contained in the spray. There is a range of opinions on the definition of the optimum droplet size spectrum for a spray, depending on the product and target. Small droplets may be prone to off-target movements while large droplets may bounce, shatter, or roll off leaves and other targets. The control of broadleaf weeds and herbicide deposition on the ground can be optimized with relatively large droplets $(>200 \mu \mathrm{m})$. These larger droplets minimize spray drift potential as long as the water or carrier volume rate is sufficiently high to provide coverage. Spray collection on narrow leaf weeds such as grasses may be better with smaller droplets $(100 \div 200$ $\mu \mathrm{m})$. In the present paper, the focus is on the control of a range of weeds including grasses.

When considering spraying systems, it is important to carefully characterize the nozzles or atomizers being used to apply the pesticide. Nozzle selection greatly influences droplet size, which in turn greatly impacts both the biological efficacy as well as the off-target movement of pesticides through physical particle drift, volatilization, and run-off through water movement of sprays which reach the ground (soil). To reduce a loss of pesticide and mitigate damage to the environment, it is necessary to develop information about the quality of the nozzles which are approved for pesticide application (Hewitt 1997; Womac 
et al. 1999; Giles et al. 2005; Guler et al. 2007; Hewitt 2008b; Czaczyk 2012). It is the responsibility of the sprayer operator to use the information available, so that appropriate information about the spray nozzles is utilized when making pesticide applications. It is the role of the government to ensure that information is developed and available to the applicators. Voluntary procedures used for many years, for example in Germany, do not always provide all of the information that is necessary to make a fully informed decision about which spray nozzles to select for specific pesticides. This is especially true in Poland where there is no recognized certification and no consultative centre like the Deutsche Landwirtschaftliche Gemeinschaft (DLG e.V. - German Agricultural Society). A similar role in Poland was fragmentarily served (safety - CE certificate) by: the Industrial Institute of Agricultural Engineering in Poznan (IIAE), also formerly the Institute for Building Mechanization and Electrification of Agriculture (IBMEA), and redactions of agricultural journals. The certification research of agricultural machines in Poland is without the tradition and the marketing which certification provides in Germany. It should be noted that in Germany, the plant protection equipment group (sprayers, misters, seed treatment applicators, atomizers and other machines) is the only group of equipment excluded from the machines tested by the DLG. In Germany, the Julius Kühn Institute in Braunschweig (www. jki.bund.de) evaluates and certifies this unique group of machines used for the application of pesticides (JKI 2012).

The aim of this study was to determine, according to international methods, the spray droplet size characteristics of nozzles developed and produced in Poland.

\section{MATERIALS AND METHODS}

The full range of air induction nozzles offered by MMAT was included in this study. The nozzles tested included the following:

short body (21 mm length) twin jet: EŻKT 11003, EŻKT 11004,

single jet: EŻK 11002, EŻK 110025, EŻK 11003, EŻK 11004,

long body (37 mm) single jet: EŻ 110025, EŻ 11003 and EŻ 11004.

A visual inspection of the spray pattern from each nozzle was made to ensure the nozzle was not damaged, plugged or in some other way not working properly. The flow rate $\mathrm{q}_{\mathrm{r}}(\mathrm{l} / \mathrm{min})$ was measured according to ISO 10625 standard (ISO 2005). Then, one of ten nozzles for each type tested was chosen, to investigate the spray quality. Characteristics of the tested nozzles were determined by spraying tap water for the three pressures: 250, 350 and $450 \mathrm{kPa}$. The physical properties of the spray liquid play a significant role in the droplet size. Some researchers e.g.: Hewitt (2008b), De Schampheleire et al. (2009) also evaluated influence of the physical properties such as the dynamic surface tension (DSF). The DSF of used water was estimated by the KSV optical tensiometer Theta Lite, equipped with a camera taking over 60 photos per second (frame interval $16 \mathrm{~ms}$ ) was $\sim 63 \mathrm{mN} / \mathrm{m}$ (at a surface lifetime age of $16 \mathrm{~ms}$ ). Measurements of the droplet sizes conduct- ed in this study were performed using a Sympatec HELOS Vario ${ }^{\circledR}$ laser diffraction particle size analyzer (Sympatec $\mathrm{GmbH}$ ) to measure the droplet size spectrum in the dynamic size range $0.5 \div 3,500 \mu \mathrm{m}$. Sympatec HELOS Vario ${ }^{\circledR}$ laser diffraction particle size analyzer (Sympatec $\mathrm{GmbH}$ ) operates on the principle of laser beam diffraction with the HELOS instrumentation. This device allows the measurement of particles in movement at speeds up to $100 \mathrm{~m} / \mathrm{s}$. The measured droplets were catalogued in 30 size classes. The study was conducted in the West Central Research and Extension Center of the University of Nebraska-Lincoln in North Platte, Nebraska, USA. The HELOS laser system has an emitter and receiver, which were positioned across from each other and outside of the measurement chamber. During the measurement, the nozzles were horizontally moved at approximately $0.2 \mathrm{~m} / \mathrm{s}$ so the entire spray plume emitted from the nozzle passed through the measurement zone of the laser diffraction instrument. Due to the fact that air temperature and liquid atomization are related (Spillman 1984; Miller et al. 2005), air temperature at the time of the testing was recorded. The air temperature was similar to the fluid temperature (tap water) which was approximately $18^{\circ} \mathrm{C}$. The relative air humidity fluctuated between 63 to $66 \%$. A single replication was comprised of traversing the entire spray plume through the SympaTec ${ }^{\circledR}$ Helos laser beam at a distance of $0.2 \mathrm{~m}$ above the laser beam of the laser diffraction instrument. The ceramic Albuz air induction flat fan nozzles from Coorstek (former Saint-Gobain Solcera): AVI 8001, AVI 8002, AVI 11002 and AVI 11003 were included in the test, to compare the characteristics of MMAT nozzles to a well-known set of nozzles.

\section{RESULTS AND DISCUSSION}

The obtained results are presented in table 1 and figures 1, 2, and 3. A typical set of spraying quality parameters according to international standard ASAE S571.1 (2009) are shown. The $D_{v 10}$ value is the diameter below which $10 \%$ of the liquid volume is atomized into droplets with diameters below this value.

The $D_{v 90}$ value is the diameter below which $90 \%$ of the liquid volume is atomized into the smaller droplets $(10 \%$ of the volume is atomized in spray droplets with diameters larger than this value). The average volume diameter $\mathrm{D}_{\mathrm{v} 50}$ is often used interchangeably with VMD (Volume Median Diameter). The value is where half of the sprayed liquid is atomized into droplets larger than this value, and half of the droplets are smaller than this value. Volume Median Diameter is a recognized factor of the spray quality. Colors (graphs) are used in figures 1, 2 and 3 correspond with the visi flow color code. Nozzles are according to the standard ISO 10625 (2005) depending on the flow rate. Additionally, the percent of the spray volume having a diameter less than $100 \mu \mathrm{m}$ (often considered to be the driftable fraction of the spray), and the fraction $(100 \div 200 \mu \mathrm{m})$ with highest productivity of droplet number from the volume unit (Matthews 2000) were also computed. The RS, which is a dimensionless value of the range of the droplet sizes in the generated population of droplets (homogeneity), were determined. 


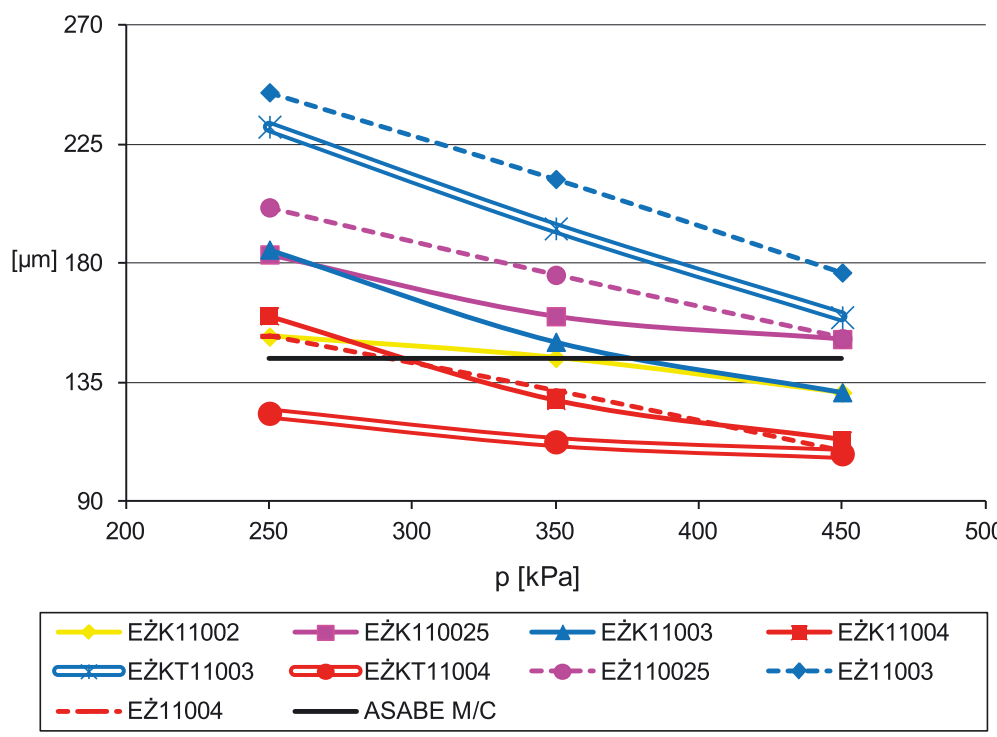

Fig. 1. Spray characteristics for tested MMAT nozzles interpreted with $D_{\mathrm{v} 10}$

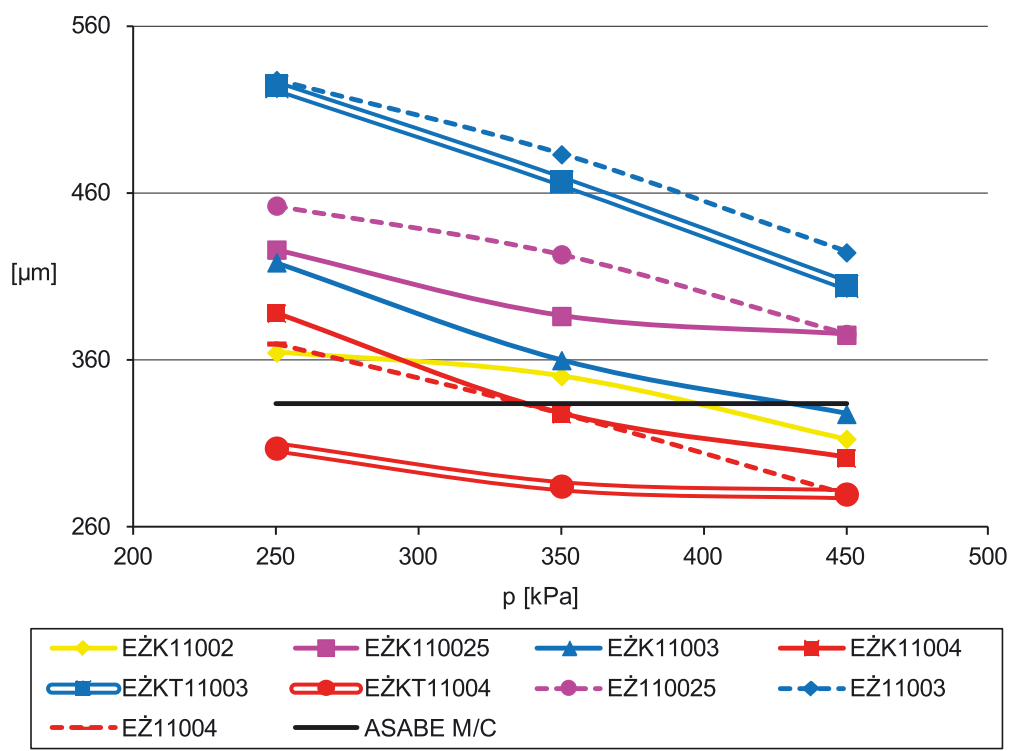

Fig. 2. Spray characteristics for tested MMAT nozzles interpreted with VMD $\left(D_{v 50}\right)$

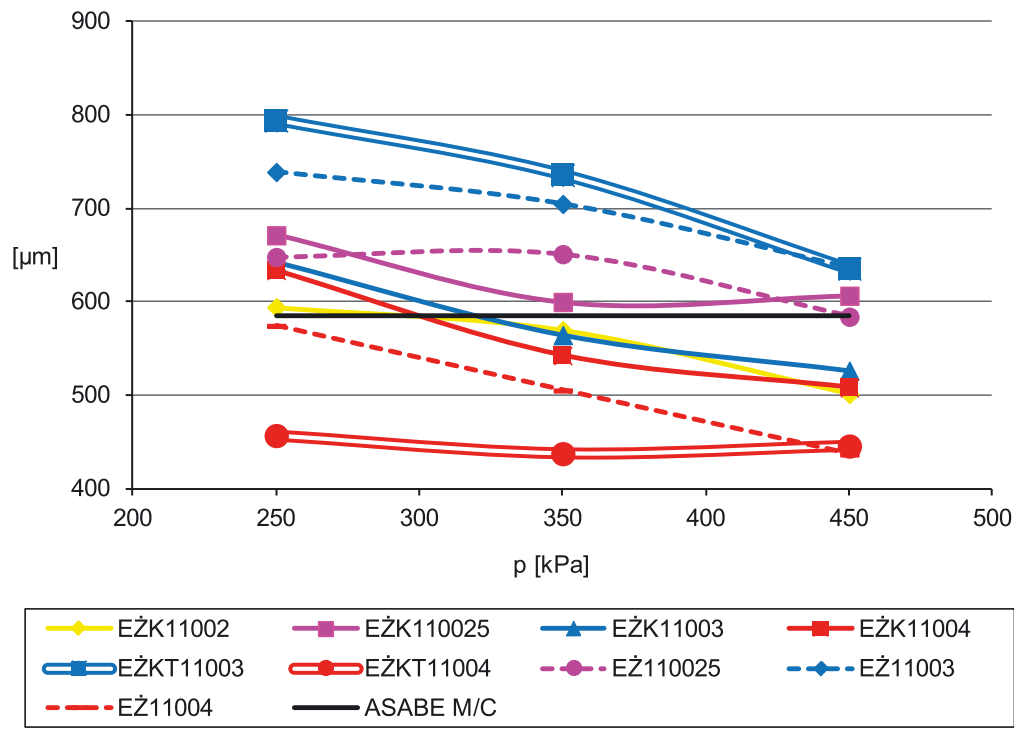

Fig. 3. Spray characteristics for tested MMAT nozzles interpreted with $D_{v 90}$ 


$$
R S=\left(D_{v 90}-D_{v 10}\right) D_{v 50}^{-1}
$$

The values of $D_{\mathrm{v} 10}$ for the studied nozzles varied for different orifice sizes and pressures. The results were similar to what has been reported for nozzles made by other companies (Womac et al. 1999; Giles et al. 2005; Guler et al. 2007; Nuyttens et al. 2007a; Nuyttens et al. 2007b). The $D_{v 10}$ value decreased with increasing pressure. The tested nozzles ranged from 152 to $232 \mu \mathrm{m}$ at $250 \mathrm{kPa}$, from 128 to $193 \mu \mathrm{m}$ at $350 \mathrm{kPa}$, and from 113 to $160 \mu \mathrm{m}$ at $450 \mathrm{kPa}$. The $\mathrm{D}_{\mathrm{v} 90}$ values changed similarly with a decrease in droplet size resulting from increasing pressure. For the pressure of $250 \mathrm{kPa}$, the nozzle ranged in $\mathrm{D}_{\mathrm{v} 90}$ val- ue from 594 to $794 \mu \mathrm{m}$, at $350 \mathrm{kPa}$ from 542 to $736 \mu \mathrm{m}$, and at $450 \mathrm{kPa}$ the values ranged from 501 to $635 \mu \mathrm{m}$.

Spray classification was determined according to the international standard ASAE S572.1. (2009). Corresponding colors were used (Table 1) also for ASABE spray classes (column 8). At the lowest test pressure $(250 \mathrm{kPa})$, the nozzles EŻK 11002, EŻ 110025, EŻK 110025, EŻ 11003, EŻK 11003 and EŻK 11004 were characterized as Coarse sprays (blue color). The EŻKT 11004 and EŻ 11004 nozzles at $250 \mathrm{kPa}$ were Medium sprays (yellow color). The EŻKT 11003 nozzle at a pressure of $250 \mathrm{kPa}$, and AVI 11003 at a pressure of $276 \mathrm{kPa}$ were characterized as Very Coarse sprays (green color).

Table 1. Spray characteristics of MMAT nozzles determined by using laser diffraction according to ASAE standard S.572.1 (2009) (water $\sim 18^{\circ} \mathrm{C}$, DST $\sim 63 \mathrm{mN} / \mathrm{m}$ )

\begin{tabular}{|c|c|c|c|c|c|c|c|c|}
\hline Nozzle type & Pressure & $<100 \mu \mathrm{m}$ & $100 \div 200 \mu \mathrm{m}$ & $\mathrm{D}_{\mathrm{v} 10}$ & $\operatorname{VMD}\left(\mathrm{D}_{\mathrm{v} 50}\right)$ & $\mathrm{D}_{\mathrm{v} 90}$ & $\begin{array}{c}\text { ASAE } \\
\text { classification }\end{array}$ & RS \\
\hline color ISO² & $\mathrm{kPa}$ & $\%_{\mathrm{vol}}$ & $\%_{\mathrm{vol}}$ & $\mu \mathrm{m}$ & $\mu \mathrm{m}$ & $\mu \mathrm{m}$ & class + color $^{1}$ & - \\
\hline EŻK 11002 & 250 & 4.5 & 14.7 & 152.5 & 364.6 & 594.3 & Coarse & 1.21 \\
\hline EŻ 110025 & 250 & 2.4 & 8.5 & 201.2 & 452.4 & 647.9 & Coarse & 0.99 \\
\hline EŻK 110025 & 250 & 3.0 & 10.2 & 183.5 & 426.1 & 671.2 & Coarse & 1.14 \\
\hline EŻ 11003 & 250 & 1.6 & 5.8 & 244.7 & 527.6 & 738.9 & Coarse & 0.94 \\
\hline Ė̇K 11003 & 250 & 2.8 & 10.1 & 185.3 & 418.5 & 642.0 & Coarse & 1.09 \\
\hline EŻKT 11003 & 250 & 1.7 & 6.5 & 231.7 & 523.9 & 793.9 & Very Coarse & 1.07 \\
\hline EŻ 11004 & 250 & 4.7 & 13.2 & 152.7 & 369.9 & 574.2 & Medium & 1.14 \\
\hline EŻK 11004 & 250 & 3.1 & 12.9 & 160.3 & 388.1 & 633.5 & Coarse & 1.22 \\
\hline EŻKT 11004 & 250 & 7.0 & 18.7 & 123.5 & 307.4 & 456.9 & Medium & 1.08 \\
\hline AVI 11003 & 276 & 1.7 & 6.0 & 237.6 & 506.6 & 752.6 & Very Coarse & 1.02 \\
\hline EŻK 11002 & 350 & 4.9 & 15.5 & 144.4 & 350.4 & 569.6 & Medium & 1.21 \\
\hline EŻ 110025 & 350 & 3.4 & 10.5 & 175.8 & 423.3 & 651.0 & Coarse & 1.12 \\
\hline EŻK 110025 & 350 & 3.5 & 12.8 & 160.2 & 386.4 & 599.8 & Coarse & 1.14 \\
\hline EŻ 11003 & 350 & 2.3 & 7.6 & 212.0 & 483.2 & 704.7 & Coarse & 1.02 \\
\hline Ė̇K 11003 & 350 & 4.7 & 14.1 & 150.5 & 360.0 & 564.3 & Medium & 1.15 \\
\hline EŻKT 11003 & 350 & 2.7 & 8.9 & 193.3 & 466.8 & 735.6 & Coarse & 1.16 \\
\hline EŻ 11004 & 350 & 6.3 & 16.8 & 132.0 & 327.9 & 505.1 & Medium & 1.14 \\
\hline EŻK 11004 & 350 & 4.9 & 17.9 & 128.3 & 327.9 & 542.4 & Medium & 1.26 \\
\hline EŻKT 11004 & 350 & 8.6 & 21.8 & 112.7 & 284.6 & 437.5 & Medium & 1.14 \\
\hline EŻK 11002 & 450 & 5.9 & 19.3 & 131.3 & 312.9 & 501.4 & Medium & 1.18 \\
\hline EŻ 110025 & 450 & 4.6 & 13.2 & 151.8 & 375.6 & 584.0 & Coarse & 1.15 \\
\hline EŻK 110025 & 450 & 4.5 & 13.7 & 151.5 & 375.2 & 606.5 & Coarse & 1.21 \\
\hline EŻ 11003 & 450 & 3.4 & 10.3 & 176.7 & 424.5 & 637.2 & Coarse & 1.08 \\
\hline EŻK 11003 & 450 & 6.3 & 17.2 & 131.5 & 327.8 & 526.3 & Medium & 1.20 \\
\hline EŻKT 11003 & 450 & 4.2 & 12.0 & 159.8 & 404.4 & 635.5 & Coarse & 1.18 \\
\hline EŻ 11004 & 450 & 9.3 & 22.0 & 109.2 & 279.3 & 439.3 & Medium & 1.17 \\
\hline EŻK 11004 & 450 & 5.3 & 20.4 & 113.4 & 301.4 & 508.0 & Medium & 1.31 \\
\hline EŻKT 11004 & 450 & 9.4 & 22.5 & 108.2 & 279.9 & 445.7 & Medium & 1.21 \\
\hline AVI 8001 & 450 & 7.1 & 15.1 & 125.5 & 346.8 & 596.5 & Medium & 1.28 \\
\hline AVI 8002 & 500 & 3.2 & 9.0 & 191.6 & 433.5 & 699.3 & Coarse & 1.17 \\
\hline AVI 11002 & 450 & 3.2 & 9.8 & 182.6 & 428.7 & 677.7 & Coarse & 1.15 \\
\hline AVI 11003 & 450 & 2.9 & 9.0 & 188.3 & 425.4 & 675.9 & Coarse & 1.15 \\
\hline
\end{tabular}

${ }^{1}$ the color (Table 1) as spray class (column 8) was determined according to ASAE S572.1. standard (2009), what is different to color code (column 1) according to flow rate ${ }^{2}$, determined with ISO 10625 (2005) on the figures 1, 2 and 3; VMD - Volume Median Diameter RS - relative span 
While droplet size typically increases as a nozzle's orifice size increases, the EŻKT 11004 nozzle is an exception. Taking into consideration all nozzles sizes and pressures tested, the EŻKT 11004 is significantly smaller both in droplet size and size classification. However the behaviour of EŻKT 11004 relative to decreasing droplet size with increasing pressure (Table 1), is consist with typical hydraulic nozzle behaviour. There was a significantly smaller droplet size for all 04 flow rate (ISO 2005) MMAT nozzles tested, relative to the other nozzles tested. The reason for the smaller droplet size is likely an artefact of the manufacturing of this particular nozzle. Knowing the droplet characteristics of this particular nozzle will allow applicators and advisors to use it where appropriate.

At the pressure $350 \mathrm{kPa}$, the EŻK 11002, EŻK 11003, EŻ 11004, EŻK 11004 and EŻKT 11004 nozzles were characterized as Medium sprays, and EŻ 110025, EŻK 110025, EŻ11003, EŻKT 11003 were characterized as Coarse sprays. Albuz nozzles were not classified at this pressure.

At the pressure $450 \mathrm{kPa}$, the EŻK 11002, EŻK 11003 , EŻ 11004, EŻK 11004, EŻKT 11004 and AVI 8001 nozzles were classified as having a Medium spray quality. The EZ 110025, EŻK 110025, EŻ 11003, EŻKT 11003, AVI 11002 and AVI 11003 nozzles were characterized as having a Coarse spray quality. Also, the Albuz AVI 8002 nozzle at the pressure $500 \mathrm{kPa}$, was characterised as having a Coarse spray quality.

The EŻ 110025 EŻK 110025 and EŻKT 11004 nozzles showed a specific behaviour. The EŻ 110025 nozzle at pressures 250 and $350 \mathrm{kPa}$ generated very similar $\mathrm{D}_{\mathrm{v} 90}$ values, and EŻK 110025 at 350, and $450 \mathrm{kPa}$ test pressure also had very similar $\mathrm{D}_{\mathrm{v} 90}$ values. The EŻKT 11004 nozzle generated a Medium spray quality across the range of pressures tested.

The results generated in this study (spraying qualities) are similar to the preliminary results computed for these nozzles (for two pressures only: 300 and $500 \mathrm{kPa}$ ) in prior studies conducted at Forschungsanstalt Geisenheim in Germany (Czaczyk 2011b). These prior studies were made using a different piece of equipment (Malvern INSITEC).

\section{CONCLUSIONS}

Air induction flat fan nozzles from MMAT can produce Medium and Coarse sprays. Of the nozzles tested in the present study, only the EŻKT 11003 nozzle at an operational pressure of $250 \mathrm{kPa}$, generated sprays in the Very Coarse size class. Medium sprays are produced by the twin jet MMAT nozzle with orifice size 04 across a wide range of operating pressures $(250 \div 450 \mathrm{kPa})$. Coarse spray characteristics and a larger droplet size than excepted were unexpectedly produced by the twin jet MMAT size 03 nozzle. Other MMAT nozzles (operated at the lowest tested pressure $(250 \mathrm{kPa})$, generated a driftable fraction $(<$ $100 \mu \mathrm{m}$ ) below $5 \%$ of sprayed volume.

Nuyttens et al. (2007a) reported a spray volume fraction in droplet size classes below $100 \mu \mathrm{m}$ of approximately $5.5 \%( \pm 1.2)$ for the Fine/Medium spray boundary. On this basis, the relative drift risk reduction of nozzles in the present study can be inferred. With the exception of the
EŻKT 11004 nozzle (1.5\% more), all tested nozzles at low spray pressure $(250 \mathrm{kPa})$ generated lower values of $\mathrm{V}_{<100}$. The reduction was between 0.8 and $3.9 \%$. At a pressure of $350 \mathrm{kPa}$, the EŻ11004 and EŻKT 11004 nozzles exceeded this value, and other MMAT tested nozzles were below this value. At the highest test pressure $(450 \mathrm{kPa})$, the same nozzles and also EŻK 11003, and EŻK 11002 exceeded this value. Other MMAT nozzles generated droplets with the fraction most prone to drift $(<100 \mu \mathrm{m})$ below this value.

Basically, the MMAT nozzles with long body, generated sprays had the highest reduced drift characteristics - compared to other MMAT (the same orifice size) tested nozzles. The coefficient of driftable fraction $(<100 \mu \mathrm{m})$ was at the lower pressure $(250 \mathrm{kPa})$ on the same value as for the twin jet EŻKT 11003 nozzle and the Albuz AVI 11003 nozzle at $276 \mathrm{kPa}$ working pressure. Only at a higher test pressure $(450 \mathrm{kPa})$ were the results for EŻ 11003 (long body) similar to EŻK 11003.

Also at the highest tested pressure $(450 \mathrm{kPa})$, the EŻ 11003 (long body) nozzle had the lowest value of $<100 \mu \mathrm{m},(3.4 \%)$ among the MMAT nozzles which were tested. These values were similar to those of the Albuz size 02 and 03 nozzles which were all within the Coarse size class.

All of the MMAT size 04 nozzles were classified as Medium sized with the exception of the EŻK 11004 at the lowest pressure $(250 \mathrm{kPa})$ which was Coarse.

By covering a range of droplet size spectra up to Very Coarse, the nozzles tested in this study should allow a wide range of agrichemicals to be applied according to Best Management Practices (BMPs). In Poland, BMPs (Pruszyński and Wolny 2009) should be extended to include a requirement for nozzle classification according to droplet size, that follows international standards. Many countries such as the UK and Germany, operate such schemes. Examples of spray quality for pesticide regulation and decision support can be found on pesticide labels, best management practices, and standards in several countries. For example, the Australian government's regulatory organisation, the Australian Pesticides and Veterinary Medicines Authority (APVMA) requires the use of Coarse sprays for the application of herbicides such as 2,4-D and similar examples exist for other products and countries including Poland. For example, the label for one of the most common herbicides, Roundup 360 SL, references Medium spray quality on labels in Poland.

The MMAT nozzles tested in this study allow practical field spray application rates from 100 to 450 1/ha with a driving speed between 5 and $10 \mathrm{~km} / \mathrm{h}$ at working pressures of 250 to $450 \mathrm{kPa}$, to produced Medium to Coarse sprays as required for most spraying in Poland.

In Poland, we do not recommend use of the $\mathrm{D}_{\mathrm{v} 90}$ value in spray classification where drift management is the key goal. The reason for this statement is because some sprays are classified finer or coarser by this parameter than they are at the lower parts of the cumulative volumetric droplet size curve. For example, using the $\mathrm{D}_{\mathrm{v} 90}$ for classification of the nozzle EŻKT 11003 at $250 \mathrm{kPa}$ working pressure, yields a Very Coarse category whereas the VMD and/or $D_{\mathrm{v} 10}$ values suggest it is, in fact, a Coarse spray. Similar suggestions relating to misclassified noz- 
zles when using the Standard ASAE S572.1 (2009) were previously made by Teske et al. for the USA (2003) and Hewitt for Australia (2008a).

Nuyttens et al. (2007b) categorised a Hardi ISO F11003 flat fan nozzle (at pressure $300 \mathrm{kPa}$ ) as reference (zero reduction) in spray drift potential. Czaczyk (2012) determined for the same size Albuz AXI ISO 11003 reference nozzle, a significant higher value $(13.8 \%)$ of droplets which were smaller than $100 \mu \mathrm{m}$ compared to Nuyttens et al. (2007a) (5.5\%). The main reason for these differences is the use of different sampling systems for droplet size and the use of sprays with different physical properties. Lund (2000) suggests that there is not always a high correlation between the measured drift prone droplet fraction $\left(\mathrm{V}_{<100}\right)$ and actual spray drift potential in the field.

\section{ACKNOWLEDGEMENTS}

We wish to thank: the District Director of the West Central Research and Extension Center in North Platte: Dr. Don C. Adams, University of Nebraska-Lincoln, for access to the laboratory, and Ryan Henry, Geff Golus, and Annah Masten for their technical support.

\section{REFERENCES}

ASAE S572.1. 2009. Spray Nozzle Classification by Droplet Spectra.

Czaczyk Z. 2012. Spray classification for selected flat fan nozzles. J. Plant Prot. Res. 52 (1): 180-183.

Czaczyk Z. 2011a. Nierównomierność rozkładu poprzecznego cieczy i podatność wybranych rozpylaczy na zużycie. Technika Rolnicza Ogrodnicza Leśna 5: 16-18.

Czaczyk Z. 2011b. Wstępne wyniki oceny jakości pracy rozpylaczy eżektorowych MMAT. Technika Rolnicza Ogrodnicza Leśna 6: 10-12.

Czaczyk Z., Kleisinger S. 2002. Drift potential of boom-mounted antidrift nozzles measured in a wind tunnel. 10th IUPAC International Congress on the Chemistry of Crop Protection. Basel, August 4-9th. Vol. 1, p. 415.

De Schampheleire M., Nuyttens D., Baetens K., Cornelis W., Gabriels D., Spanoghe P. 2009. Effects on pesticide spray drift of the physicochemical properties of the spray liquid. Precision Agric. 10 (5): 409-420.

Giles D.K., Downey D., Squire L. 2005. Transient Droplet Size Spectra from Trigger Sprayers Dispensing Aqueous Solutions. Transactions of Am. Soc. Agric. Eng. (ASAE) 48 (1): 63-72.

Guler H., Zhu H., Ozkan H.E., Derksen R.C., Yu Y., Krause C.R. 2007. Spray characteristics and drift reduction potential with air induction and conventional flat-fan nozzles. Transactions of the Am. Soc. Agric. Biol. Eng. (ASABE) 50 (3): $745-754$
Hewitt A.J. 1997. The importance of droplet size in agricultural spraying. Atomization and Sprays 7 (3): 235-244.

Hewitt A.J. 2001. Developments in international harmonization of pesticide drift management. Phytoparasitica 29 (2): 93-96.

Hewitt A.J. 2008a. Droplet size spectra classification categories in aerial application scenarios. Crop Prot. 27 (9): 1284-1288.

Hewitt A.J. 2008b. Spray optimization through application and liquid physical property variables-I. Environmentalist 28 (1): 25-30.

ISO 10625. 2005. Equipment for Crop Protection. Sprayer Nozzles. Colour Coding for Identification. International Standardization Organization, 12 pp.

JKI 2012. The list of certified nozzles at Julius Kühn Institute in Braunschweig:

http://www.jki.bund.de/fileadmin/dam_uploads/_AT/ ger\%C3\%A4telisten/anerkannte_Duesen/Tabelle $\% 20$ der\%20JKI\%20anerkannten\%20Pflanzenschutzduesen. pdf. Access: January 2012.

Lund I. 2000. Nozzles for drift reduction. Aspects Appl. Biol. 57: 97-102.

Matthews G.A. 2000. Pesticide Applications Methods. 3rd. ed. Blackwell Science, Oxford, England, $432 \mathrm{pp}$.

Miller P.C.H., Tuck C.R. 2005. Factors influencing the performance of spray delivery systems: A Review of recent developments. J. Am. Soc. Testing Materials 2 (6), 13 pp.

Nuyttens D., Baetens K., De Schampheleire M., Sonck B. 2007a. Effect of nozzle type, size and pressure on spray droplet characteristics. Biosystems Eng. 97 (3): 333-345.

Nuyttens D., De Schampheleire M., Baetens K., Sonck B. 2007b. The influence of operator-controlled variables on spray drift from field crop sprayers. Transaction of the ASABE 50 (4): 1129-1140.

Pruszyński S., Wolny S. 2009. Przewodnik Dobrej Praktyki Ochrony Roślin. Inst. Ochr. Roślin - Państwowy Inst. Badawczy, Poznań, 90 pp.

Southcombe E.S.E., Miller P.C.H., Ganzelmeier H., van de Zande J.C., Miralles A., Hewitt A.J. 1997. The international (BCPC) spray classification system including a drift potential factor. p. 371-380. In: Proc. BCPC Crop Protection ConferenceWeeds. Brighton, UK, 17-20 November 1997, 1202 pp.

Spillman J.J. 1984. Spray impaction, retention and adhesion: an introduction to basic characteristics. Pestic. Sci. 15 (2): 97-106.

Teske M.E., Hewitt A.J., Valcore D.L. 2003. Drift and nozzle classification issues with ASAE standards S572 Aug99 Boundaries. Paper Number: AA03-001, written for presentation at the 2003 ASAE/NAAA Technical Session sponsored by ASAE Technical Committee PM23/6/2. 37th Annual National Agricultural Aviation Association Convention Silver Legacy Hotel and Casino, Reno, NV, December 8, 9 pp.

Womac A.R., Maynard II R.A., Kirk I.W. 1999. Measurement variations in reference sprays for nozzle classification, Transaction of the ASAE 42 (3): 609-616. 